\title{
Influence of Vanadium Content on Hot Deformation Behavior of Low-Carbon Boron Microalloyed Steel
}

\author{
Kwang-Su Kim ${ }^{1} \cdot$ Lin-Xiu Du $^{2} \cdot$ Hyo-sung Choe ${ }^{1} \cdot$ Tae-Hyong Lee ${ }^{1} \cdot$ Gyong-Chol Lee ${ }^{1}$
}

Received: 19 September 2019 / Revised: 8 November 2019 / Published online: 5 February 2020

(c) The Chinese Society for Metals (CSM) and Springer-Verlag GmbH Germany, part of Springer Nature 2020

\begin{abstract}
Single-pass compression tests were performed to investigate the hot deformation behavior of low-carbon boron microalloyed steel containing three various vanadium contents at $900-1100{ }^{\circ} \mathrm{C}$ and strain rate of $0.01-10 \mathrm{~s}^{-1}$ using the MMS-300 thermal mechanical simulator. The flow stress curves of investigated steels were obtained under the different deformation conditions, and the effects of the deformation temperature and strain rate on the flow stress were discussed. The characteristic points of flow stress were obtained from the stress dependence of strain hardening rate; the activation energy of investigated steels was determined by the regression analysis; the flow stress constitutive equations were developed; the effect of vanadium content on the flow stress and dynamic recrystallization (DRX) was investigated. The result showed that the flow stress and activation energy $\left(316.5 \mathrm{~kJ} \mathrm{~mol}^{-1}\right)$ of the steel containing $0.18 \mathrm{wt} \% \mathrm{~V}$ were significantly higher than those of the steels with $0.042 \mathrm{wt} \%$ and $0.086 \mathrm{wt} \% \mathrm{~V}$, which was related to the increase in solute drag and precipitation effects for higher vanadium content. DRX analysis showed that the addition of vanadium can delay the initiation and the rate of DRX.
\end{abstract}

Keywords Boron microalloyed steel $\cdot$ Vanadium $\cdot$ Flow stress $\cdot$ Hot deformation $\cdot$ Dynamic recrystallization

\section{Introduction}

The development of low-cost high-performance microalloyed steel is one of the important research fields of steel. In the research works on the high-strength high-toughness steels, the addition of boron to microalloyed steel with $\mathrm{Ti}$, $\mathrm{V}$ and $\mathrm{Nb}$ has been widely used to improve the mechanical properties of steel $[1,2]$. Boron is regarded as one of the most effective elements to realize the transformation strengthening in the steel [3]. The adding of boron to the low-carbon low-alloy steels increases remarkably the hardenability of steel [4], and it allows the expensive elements

Available online at http://link.springer.com/journal/40195.

Kwang-Su Kim

kks7546@star-co.net.kp

$\triangle$ Lin-Xiu Du

dulx@ral.neu.edu.cn

1 Department of Materials Science and Engineering, Kim Chaek University of Technology, Pyongyang 999093, Democratic People's Republic of Korea

2 State Key Laboratory of Rolling and Automation, Northeastern University, Shenyang 110819, China such as $\mathrm{Cr}$, Ni and Mo to replace or reduce [5]. Generally, the strengthening effect of boron is based on the assumption that solute boron atoms easily segregate to prior austenite grain boundaries before the transformation of austenite to ferrite, decreasing the grain boundary energy while delaying the phase transformation process $[6,7]$. Due to this effect of boron on the phase transformation and hardenability, boron microalloyed steels have been widely used in buildings, ship structure, automobile and machine industry $[8,9]$. Meanwhile, it has been well known that vanadium is the most commonly used precipitation strengthening element [10]. Particularly, many fine particles of vanadium carbonitride are precipitated and they cause remarkable precipitation strengthening in the phase transformation or the heat preservation process during controlled rolling and controlled cooling process. In consequence, combining the phase transformation effect of boron with precipitation strengthening effect of vanadium during the controlled rolling and controlled cooling process, the studies on the development of a new low-cost high-performance microalloyed steel have been extensively conducted $[11,12]$. Such steels often do not require heat treatment, and therefore, production cost, energy and production period of the steel can be reduced. Non-heat-treated steel containing microalloying element 
such as vanadium or titanium exhibits lower toughness compared to traditional heat-treated steel [13]. In general, the strength and the toughness of the steel are increased by refining grain. During the hot deformation, it is liable for deformed steel to undergo strain hardening, dynamic recovery (DRV) or dynamic recrystallization (DRX), which leads to the change of mechanical properties and microstructures of steel. Dynamic recrystallization is significant to reduce the flow stress and to control the microstructure evolution and properties of steel during hot deformation process [14]. Therefore, in order to improve the microstructures and properties of the steel, the parameters of forming process should be controlled correctly.

Previous investigations reported the effect of vanadium on the hot deformation behavior of microalloyed steel. Most of them were mainly focused on medium or high carbon steel [15-18]. Medina and Hernandez [19] reported the effect of vanadium on low-carbon steels, but such steels contain $\mathrm{Cr}$, $\mathrm{Mo}, \mathrm{Ti}$ and $\mathrm{Nb}$ [19]. Furthermore, there are few detailed investigations into the effect of vanadium on hot deformation behavior in low-carbon boron microalloyed steel. Zhao et al. [20] reported the effect of vanadium in low-carbon steel, which did not contain boron as phase transformation strengthening element.

The purpose of this paper is to investigate the effect of vanadium content on the hot deformation behavior of lowcarbon boron microalloyed steel at different deformation temperatures and strain rates using single-pass compression tests. The flow curves and critical parameters are presented under different deformation conditions, and the flow stress constitutive equations and the kinetics of DRX are described for experimental steels. This research result may be used as reference for further study on the low-cost high-performance V-B microalloyed steel.

\section{Experimental}

Three steels with different vanadium contents of 0.042 , 0.086 and 0.18 (wt\%) were used in this investigation. They were denoted as V1, V2 and V3 steels, respectively. The chemical compositions of the experimental steels are listed in Table 1. There is about $0.002 \mathrm{wt} \%$ boron to be added into the experimental steels. The experimental steels were melted in a vacuum induction furnace, and the ingots were hot-rolled into a 12-mm-thickness plate. Cylindrical specimens with $8 \mathrm{~mm}$ in diameter and $15 \mathrm{~mm}$ in height for the hot deformation studies were machined from the hot-rolled plates. The single-pass compression tests of the experimental steels were carried out on Gleeble-1500 thermo-mechanical simulator.

For compression testing, the specimens were heated to $1150{ }^{\circ} \mathrm{C}$ at a heating rate of $20^{\circ} \mathrm{C} / \mathrm{s}$ and held for $180 \mathrm{~s}$ to be austenitized sufficiently and subsequently cooled to the given deformation temperature at a cooling rate of $10{ }^{\circ} \mathrm{C} / \mathrm{s}$ and held for $30 \mathrm{~s}$ to eliminate temperature gradient. The compression test was conducted at different deformation temperatures $\left(900,950,1000,1050,1100{ }^{\circ} \mathrm{C}\right)$ and strain rates $\left(0.01,0.1,1,10 \mathrm{~s}^{-1}\right)$, and the true strain achieved was 0.8 . The experimental data obtained during compression test were converted into flow stress curves using the standard method. In order to observe the effect of vanadium on prior austenite grain size and precipitate formation in experimental steels, specimens were deformed at a strain rate of $0.01 \mathrm{~s}^{-1}$ and the temperature of $950{ }^{\circ} \mathrm{C}$ and then quenched in water subsequently. After then, the specimens were sectioned along radius direction mechanically polished. The microstructure of prior austenite was observed by means of a Leica DMIRM optical microscope after being etched in saturated picric acid solution. The morphologies and compositions of precipitates in the quenched specimens were investigated by using FEI Tecnai G2 F20 transmission electron microscopy (TEM) and an energy-dispersive X-ray spectroscopy (EDX). The thin foils of $\varphi 3 \mathrm{~mm}$ for TEM analysis were electro-polished in a $8 \mathrm{vol} \%$ perchloric acid-alcohol solution.

\section{Results and Discussion}

\subsection{True Stress and True Strain}

The flow stress curves of three experimental steels deformed at various temperatures and strain rates are presented in Fig. 1. It is seen that the deformation temperature and the strain rate have a great effect on the hot deformation behavior of the experimental steels. The flow stress of each experimental steel increases considerably with decreasing the deformation temperature and increasing the strain rate. Generally, during the high temperature deformation of
Table 1 Chemical composition of the experimental steels (wt\%)

\begin{tabular}{|c|c|c|c|c|c|c|c|c|c|c|}
\hline Steel & $\mathrm{C}$ & $\mathrm{Si}$ & $\mathrm{Mn}$ & $\mathrm{P}$ & S & $\mathrm{Al}$ & V & $\mathrm{Ti}$ & B & $\mathrm{N}$ \\
\hline V1 & 0.12 & 0.17 & 1.76 & 0.003 & 0.002 & 0.026 & 0.042 & $<0.005$ & 0.0021 & 0.004 \\
\hline V2 & 0.12 & 0.14 & 1.76 & 0.002 & 0.002 & 0.027 & 0.086 & $<0.005$ & 0.0019 & 0.004 \\
\hline V3 & 0.11 & 0.13 & 1.77 & 0.003 & 0.002 & 0.025 & 0.180 & $<0.005$ & 0.0020 & 0.004 \\
\hline
\end{tabular}

$\mathrm{Ti}$ and $\mathrm{N}$ were not added purposefully 

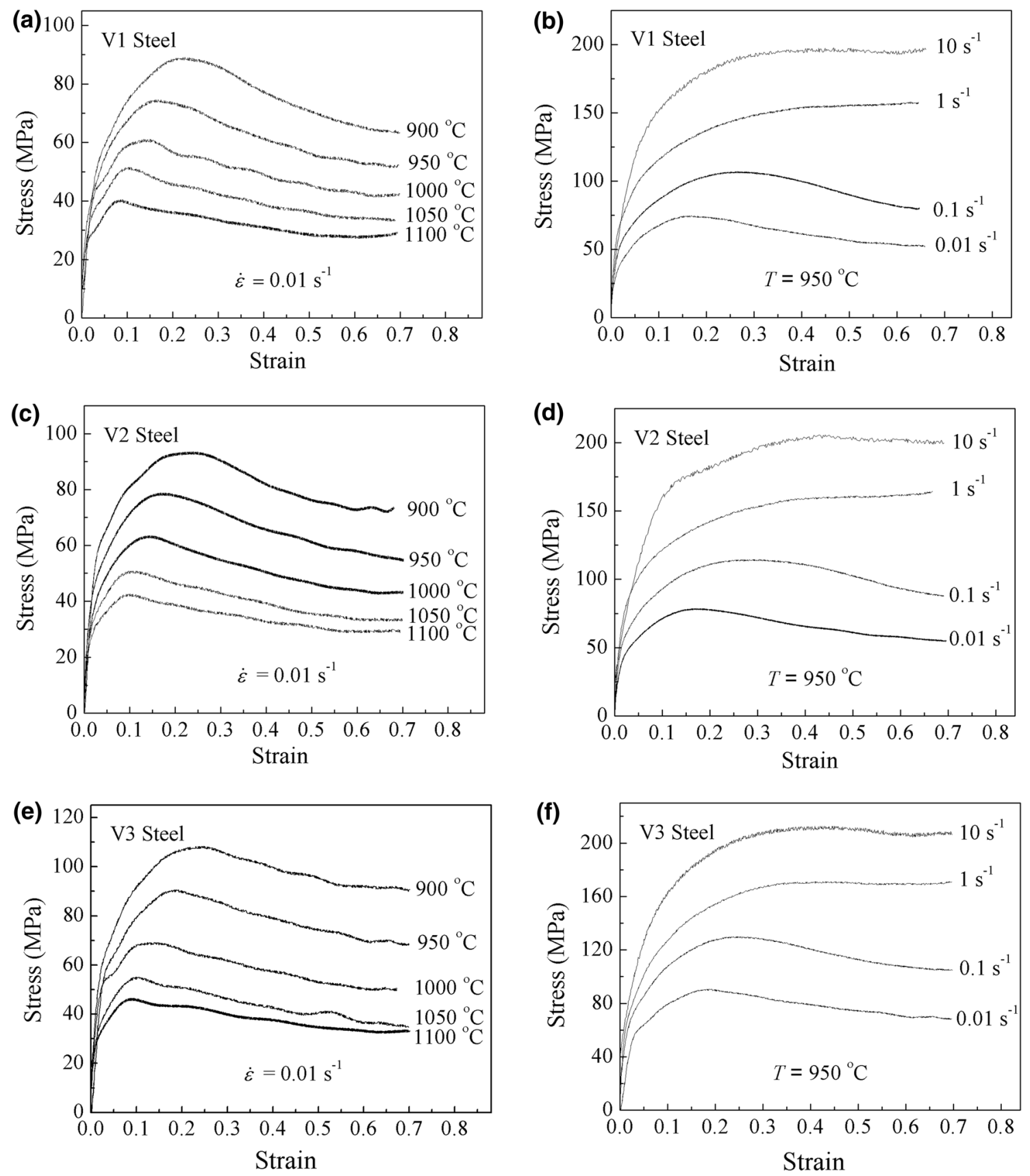

Fig. 1 Stress-strain curves of experimental steels at different temperatures and strain rates

austenite, the strain hardening, dynamic recovery (DRV) or dynamic recrystallization (DRX) occur depending on the parameters of deformation process such as deformation temperature and strain rate [3,21]. All the flow curves of the experimental steels exhibit DRV or DRX behavior in given temperature and strain rate. Under the high strain rate of $10 \mathrm{~s}^{-1}$ and the temperature of $900-1100{ }^{\circ} \mathrm{C}$, three experimental steels exhibit typical DRV behavior, i.e., the flow stress is rapidly increased to a maximum value with increasing the strain and immediately reached steady-state region without any downfall, as shown in Fig. 1b, d, f. Meanwhile, at the lower strain rate $\left(0.01-0.1 \mathrm{~s}^{-1}\right)$ and the temperature of 900-1100 ${ }^{\circ} \mathrm{C}$, three experimental steels exhibit typical DRX behavior, i.e., the flow stress is increased to a peak and followed by softening toward a steady-state region, as shown in Fig. 1a, c, e. In addition, the flow curves show that the peak stress and the peak strain have a tendency to decrease with increasing deformation temperature at the same strain rate.

The DRX behavior is sensitive to the deformation temperature and processing time [22]. The lower strain rate and 
the higher deformation temperature provide the more sufficient time for energy accumulation and the higher mobility at the boundary for the nucleation and growth of dynamically recrystallized grains.

From Fig. 1, it can also be seen that the V3 steel with higher vanadium content has a higher flow resistance than V1 and V2 steels with lower vanadium content at the same deformation temperature and strain rate. This phenomenon indicates that the addition of vanadium in boron microalloyed steel produces the strain hardening effect during hot deformation. However, the flow resistances of V1 and V2 steels have only a little difference under same deformation condition.

\subsection{Characteristic Points of Flow Stress Plot}

Generally, it is difficult to determine the critical point of DRX (peak stress and strain, critical stress and strain) based on the plot of stress-strain. However, the characteristic value of the flow stress plot can be accurately determined, based on the relationship between strain hardening rate $(\theta=\mathrm{d} \sigma / \mathrm{d} \varepsilon)$ and flow stress $(\sigma)$ described by Poliak and Jonas [23, 24]. According to the literature [25], the critical stress $\left(\sigma_{\mathrm{c}}\right)$ for the initiation of DRX is obtained from the inflection point of the $\theta-\sigma$ curve, and peak stress $\left(\sigma_{\mathrm{p}}\right)$ is obtained from the point at which the strain hardening rate equals zero $(\theta=0)$ in $\theta-\sigma$ curve. When the value of strain hardening rate approaches $\sigma_{\mathrm{c}}$, the nucleation of DRX occurs [19].

Figure 2 shows $\theta-\sigma$ curves for three experimental steels at the strain rate of $0.1 \mathrm{~s}^{-1}$ and the different deformation temperatures. In each curve of Fig. 2, the value of $\theta$ decreases linearly with increasing flow stress and drop toward $\theta=0$ at peak stress. It is clearly observed that the peak stress of each experimental steel decreases with increasing deformation temperature.

Figure 3 shows $(-(\mathrm{d} \theta / \mathrm{d} \sigma))-\sigma$ curves for three experimental steels at strain rate of $0.1 \mathrm{~s}^{-1}$ and deformation temperatures of $950{ }^{\circ} \mathrm{C}$. The inflection point of each curve in Fig. 2 is obtained from the minimum value of $(-(\mathrm{d} \theta / \mathrm{d} \sigma))-\sigma$ in the curve of Fig. 3. In this way, the critical stress $\left(\sigma_{\mathrm{c}}\right)$ and peak stress $\left(\sigma_{\mathrm{p}}\right)$ at different temperatures and strain rates for V1, V2 and V3 steels were determined, and the results are presented in Fig. 4. The corresponding values of critical and peak strain are obtained based on the stress-strain data. From Fig. 4, it can be observed that the critical strain and peak strain of three experimental steels increase with increasing the strain rate and decreasing the deformation temperature.
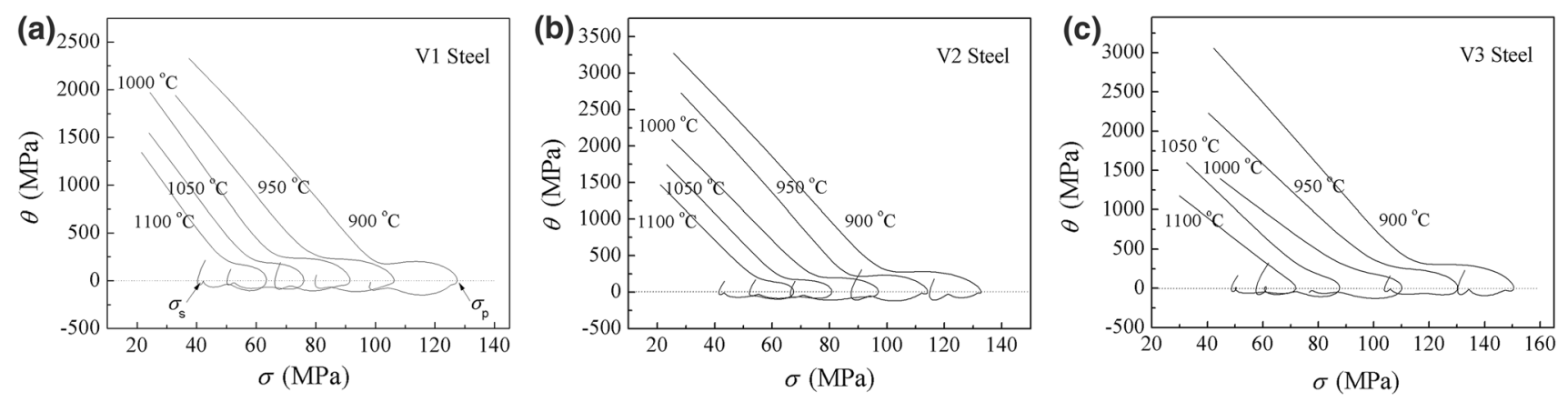

Fig. 2 Strain hardening rate $(\theta)$ versus flow stress $(\sigma)$ at strain rate of $0.1 \mathrm{~s}^{-1}$ and different deformation temperatures: a V1 steel; b V2 steel; c V3 steel
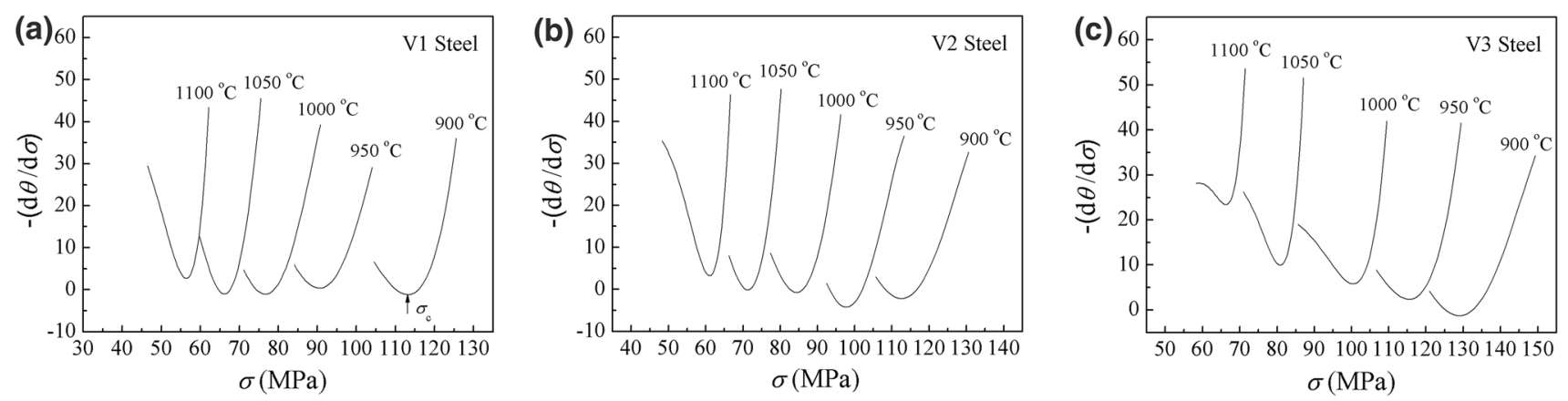

Fig. $3-(\mathrm{d} \theta / \mathrm{d} \sigma)-\sigma$ curves at strain rate of $0.1 \mathrm{~s}^{-1}$ and different temperatures: a V1 steel; b V2 steel; $\mathbf{c}$ V3 steel 

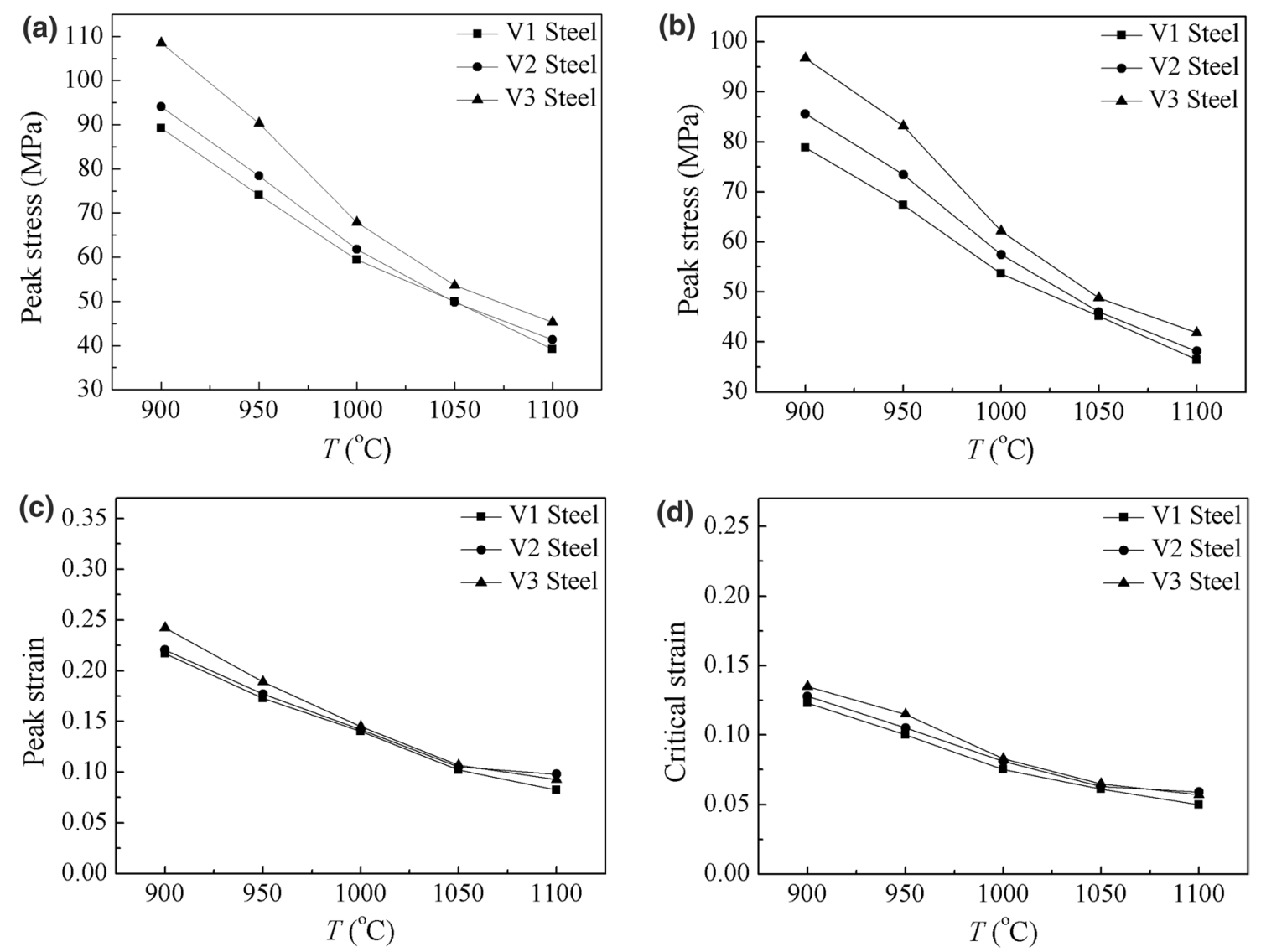

Fig. 4 Relationship between critical DRX parameters and deformation temperatures at strain rate of $0.01 \mathrm{~s}^{-1}$ : a peak stress; b critical stress; c peak strain; $\mathbf{d}$ critical strain

\subsection{Constitutive Equation and Activation Energy}

To investigate the effect of vanadium content on the hot deformation behavior, it is necessary to study the flow stress constitutive equations. The effect of temperature and strain rate on the hot deformation behavior can be described by Zener-Hollomon parameter in an exponent-type Eq. (1) [26].

$Z=\dot{\varepsilon} \exp [Q /(R T)]$,

where $Z$ is Zener-Hollomon parameter, $\dot{\varepsilon}$ the strain rate $\left(\mathrm{s}^{-1}\right)$, $Q$ the activation energy at the hot deformation $\left(\mathrm{kJ} \mathrm{mol}^{-1}\right), R$ the gas constant $\left(8.3145 \mathrm{~J} \mathrm{~mol}^{-1}\right)$, and $T$ the absolute temperature (K). The relationship between $\dot{\varepsilon}$ and $\sigma$ in the flow curve is as follows $[18,27]$.

$\dot{\varepsilon}=A_{1} \sigma^{n_{1}} \exp [-Q /(R T)] \quad \alpha \sigma<0.8$,

$\dot{\varepsilon}=A_{2} \exp (\beta \sigma) \exp [-Q /(R T)] \quad \alpha \sigma>1.2$,

$\dot{\varepsilon}=A[\sinh (\alpha \sigma)]^{n} \exp [-Q /(R T)]$ for all $\sigma$.
In the above equations, $A_{1}, A_{2}, A, n_{1}, n, \beta$ and $\alpha\left(\approx \beta / n_{1}\right)$ are the material constants; $\sigma$ is the flow stress (MPa). The power law [Eq. (2)] is suitable for lower stress $(\alpha \sigma<0.8)$, and the exponential law [Eq. (3)] is appropriate to higher stress $(\alpha \sigma>1.2)$; the hyperbolic sine law [Eq. (4)] can be used for a wide range of stress. The constitutive equations are usually established using peak stress $\left(\sigma_{\mathrm{p}}\right)[3]$.

In this research, the activation energy was calculated by using Eq. (4) at the deformation temperatures of $900-1100{ }^{\circ} \mathrm{C}$ and strain rate of $0.01-1 \mathrm{~s}^{-1}$; hence, constitutive equations of the three experimental steels were established. Taking natural logarithm on both sides of Eq. (4), the following equations are derived.

$\ln \left[\sinh \left(\alpha \sigma_{\mathrm{p}}\right)\right]=\ln \dot{\varepsilon} / n+Q /(n R T)-\ln A / n$.

When the deformation temperature is constant, the partial differentiation of Eq. (5) versus $\ln \dot{\varepsilon}$ yields

$n=\left.\frac{\partial \ln \dot{\varepsilon}}{\partial \ln \left[\sinh \left(\alpha \sigma_{\mathrm{p}}\right)\right]}\right|_{T}$. 
When the strain rate is constant, the partial differentiation of Eq. (5) versus $1 / T$ gives

$Q=\left.R n \frac{\partial \ln \left[\sinh \left(\alpha \sigma_{\mathrm{p}}\right)\right.}{\partial(1 / T)}\right|_{\dot{\varepsilon}}=R n b$.

As shown in Eqs. (6) and (7), to calculate activation energy, the value of $\alpha$ should be determined. The value of $\alpha$ is determined using the method proposed by Medina and Hernandez [19]. The variation in residual sum of squares (RSS) of $n$ with the value of $\alpha$ for V1 steel is shown in Fig. 5. It is seen that $n$ is minimum at $\alpha=0.00918$ for V1 steel. Similarly, the values of $\alpha$ for V2 and V3 steels are obtained as 0.00936 and 0.01065 , respectively. And then, according to the relationship curves of $\ln \left[\sinh \left(\alpha \sigma_{\mathrm{p}}\right)\right]$ and $\ln \dot{\varepsilon}$ at different deformation temperatures (Fig. 6a), the calculated average value of $n$ for V1 steel is 4.782; in accordance with the relationship curves of $\ln \left[\sinh \left(\alpha \sigma_{\mathrm{p}}\right)\right]$ and $1 / T$ at different strain rates (Fig. $6 b$ ), the calculated average value of the slopes is 7111.5. According to Eq. (7), the value of activation energy $Q$ for $\mathrm{V} 1$ steel is determined as $282.7 \mathrm{~kJ} \mathrm{~mol}^{-1}$.

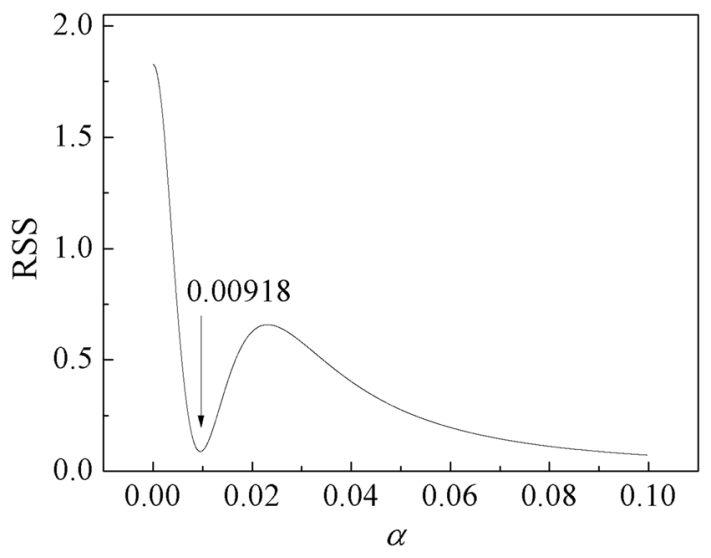

Fig. 5 Variation in residual sum of squares (RSS) of $n$ with the value of $\alpha$ for V1 steel

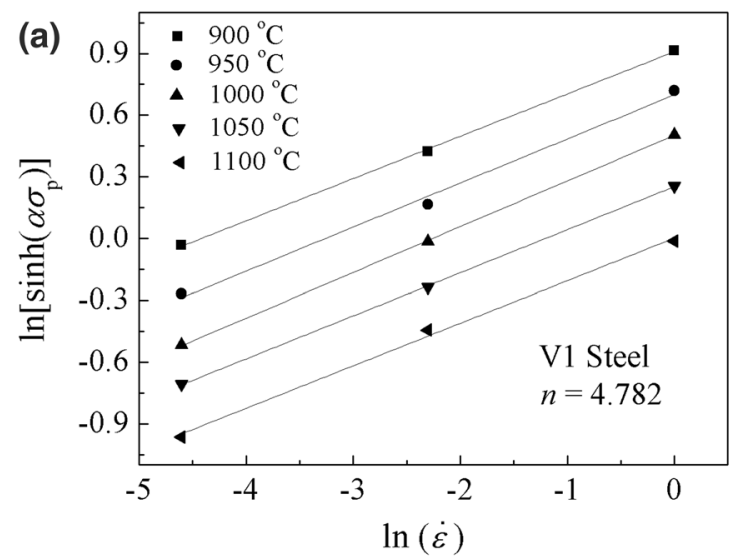

Meanwhile, from Eqs. (1) and (4), the following equation is derived

$Z=\dot{\varepsilon} \exp (Q / R T)=A\left[\sinh \left(\alpha \sigma_{\mathrm{p}}\right)\right]^{n}$.

Taking natural logarithm on both sides of Eq. (8), Eq. (9) is obtained.

$\ln Z=\ln A+n \ln \left[\sinh \left(\alpha \sigma_{\mathrm{p}}\right)\right]$.

The linear relationship between $\ln Z$ and $\ln \left[\sinh \left(\alpha \sigma_{\mathrm{p}}\right)\right]$ is presented in Fig. 7, from which A can be obtained as $9.9665 \times 10^{10}$ for V1 steel.

The parameters of the constitutive equations for experimental steels can be calculated in this way. The constitutive equations of three experimental steels are expressed as follows:

V1 steel: $\begin{aligned} Z & =\dot{\varepsilon} \exp (282700 / R T) \\ & =4.637 \times 10^{10}\left[\sinh \left(0.00918 \sigma_{\mathrm{p}}\right)\right]^{-4.782},\end{aligned}$

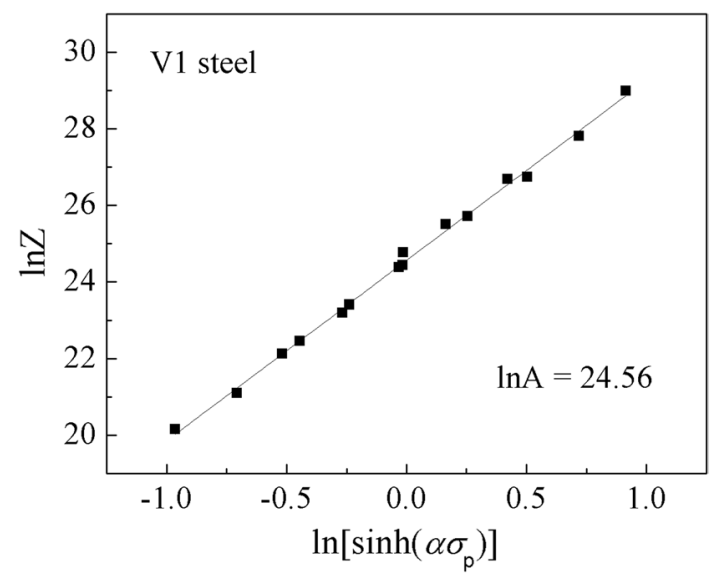

Fig. 7 Relationship between $Z$ and $\ln \left[\sinh \left(\alpha \sigma_{\mathrm{p}}\right)\right]$ for $\mathrm{V} 1$ steel

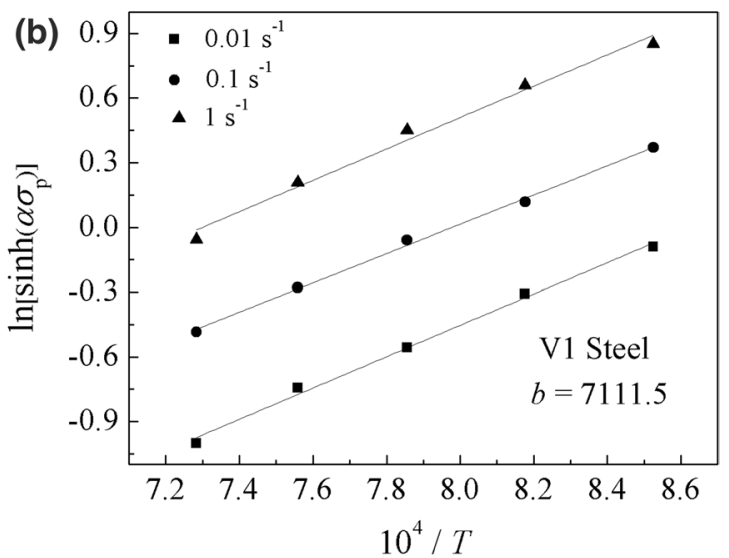

Fig. 6 Relationship among strain rate, deformation temperature and peak stress for V1 steel: a $\ln \left[\sinh \left(\alpha \sigma_{\mathrm{p}}\right)\right]-\ln \dot{\varepsilon} ; \mathbf{b} \ln \left[\sinh \left(\alpha \sigma_{\mathrm{p}}\right)\right]-10^{4} / T$ 


$$
\text { V2 steel } \begin{aligned}
Z & =\dot{\varepsilon} \exp (284600 / R T) \\
& =3.268 \times 10^{10}\left[\sinh \left(0.00936 \sigma_{\mathrm{p}}\right)\right]^{-4.641},
\end{aligned}
$$

$$
\text { V3 steel } \begin{aligned}
Z & =\dot{\varepsilon} \exp (316500 / R T) \\
& =2.391 \times 10^{11}\left[\sinh \left(0.01065 \sigma_{\mathrm{p}}\right)\right]^{-4.375} .
\end{aligned}
$$

The activation energy for hot deformation is an important physical parameter serving as indicator of deformation difficulty degree [28]. As shown in the result, the activation energy of V3 steel with high vanadium content is higher than those of V1 and V2 steels with low vanadium content, indicating the addition of vanadium in boron microalloyed steel increases activation energy of the steel during hot deformation. In previous researches, there were different reports on the effect of vanadium on the hot deformation activation energy. Zhou [29] reported that the hot deformation activation energy of $\mathrm{C}-\mathrm{Mn}$ steel can be increased by vanadium addition. It was also reported that vanadium addition in microalloyed steel had little effect on the activation energy [20].

The activation energy for hot deformation is dependent not only on the nature of metal, but also on the chemical composition [30]. When the vanadium content is lower than $0.086 \mathrm{wt} \%$, the activation energy $\left(282.7-284.6 \mathrm{~kJ} \mathrm{~mol}^{-1}\right)$ of experimental steels is similar to that reported for the lattice self-diffusion activation energy of austenite, which is about $270 \mathrm{~kJ} \mathrm{~mol}^{-1}$ [19]. The values are also close to the $Q$ value of the vanadium microalloyed steel reported in the literature [13]. That is, it is considered that vanadium addition in microalloyed steel has little effect on the activation energy. Considering the softening effect by boron addition in the microalloyed steel [31], it seems that the difference of activation energy between V1 and V2 steels is a little owing to the increase in activation energy by the vanadium addition and to the decrease in that by the boron addition.

On the other hand, the increase in vanadium content up to $0.18 \mathrm{wt} \%$ increases activation energy of experimental steel to $316.5 \mathrm{~kJ} \mathrm{~mol}^{-1}$, and it is remarkably higher than the self-diffusion activation energy of austenite. This may be due to the increase in the solute drag effect [15] and the pinning effect of precipitates [20] by increasing microalloying element content. The results show that the addition of $0.18 \mathrm{wt} \%$ vanadium is effective in hindering the lattice self-diffusion of austenite. Totally, the addition of vanadium in boron microalloyed steel increases the activation energy of experimental steels.

\subsection{Effect of Vanadium on Hot Deformation Flow Stress}

From Fig. 1, it is obvious that the flow resistance and the strain corresponding to the peak stress of V3 steel are higher than those of V1 and V2 steels under the same strain condition, which indicates that the vanadium addition can lead to increasing the flow resistance during hot deformation and to delaying the DRX of deformed austenite. And from Fig. 1, it is also seen that the flow resistances of V1 and V2 steels exhibit only slight difference.

In general, it is well known that content of alloying elements has an important influence on the activation energy for hot deformation and microalloying elements such as $\mathrm{Ti}$ and $\mathrm{Nb}$ to delay the DRX process due to the solute drag and precipitation effect $[15,20]$. As the vanadium has a high solubility in austenite, there is almost no precipitation of vanadium carbide or nitride in the austenite [32]. However, it can be expected the increases in carbon, nitrogen and vanadium contents lead to precipitation of vanadium carbides and nitrides in the austenite according to the solubility product. Akben et al. [33] indicated that both of dynamic recrystallization and dynamic precipitation may occur simultaneously at low strain rate during hot deformation.

The precipitation behavior of vanadium in the austenite is determined by the following solubility product [34].

$\lg \{[\mathrm{V}][\mathrm{N}]\}_{\gamma}=3.46-8330 / T$,

$\lg \{[\mathrm{V}][\mathrm{C}]\}_{\gamma}=6.72-9500 / T$,

where [V], [N] and [C] are the solid solute content (wt\%) of vanadium, nitrogen and carbon in the austenite, respectively.

Substituting the chemical composition of three experimental steels in Table 1 into Eqs. (13) and (14), the solution temperatures of vanadium nitrides and carbides are calculated as 878 and $780{ }^{\circ} \mathrm{C}$ in $\mathrm{V} 1$ steel, as 930 and $818^{\circ} \mathrm{C}$ in V2 steel and as 988 and $854{ }^{\circ} \mathrm{C}$ in V3 steel, respectively. From the calculation result, it can be seen that vanadium precipitates are not formed in V1 steel under the experimental condition (above $900{ }^{\circ} \mathrm{C}$ ) because the amount of vanadium in V1 steel is small. The precipitation behavior of vanadium has an effect on the microstructure of the steel and results in the inhibit action of grain growth by the solute drag and pinning effect of vanadium.

Figure 8 shows the optical microstructures of V1 and V3 steels which were deformed at the strain rate of $0.01 \mathrm{~s}^{-1}$ and the temperature of $950{ }^{\circ} \mathrm{C}$ and quenched in water subsequently. Figure 9 shows the TEM morphology and EDX analysis of precipitates formed in the above-mentioned condition. As shown in Fig. 8, V3 steel has lower grain growing tendency and smaller austenite grain than V1 steel at the same temperature and strain rate. From EDX analysis of Fig. $9 \mathrm{~b}$, the precipitates formed in $\mathrm{V} 3$ steel are $\mathrm{V}(\mathrm{C}, \mathrm{N})$ which are rich in vanadium. (Titanium and nitrogen were not added purposefully.) In V1 steel, precipitates are not observed due to relatively low content of vanadium. Based on this experimental result, it is expected that the vanadium 

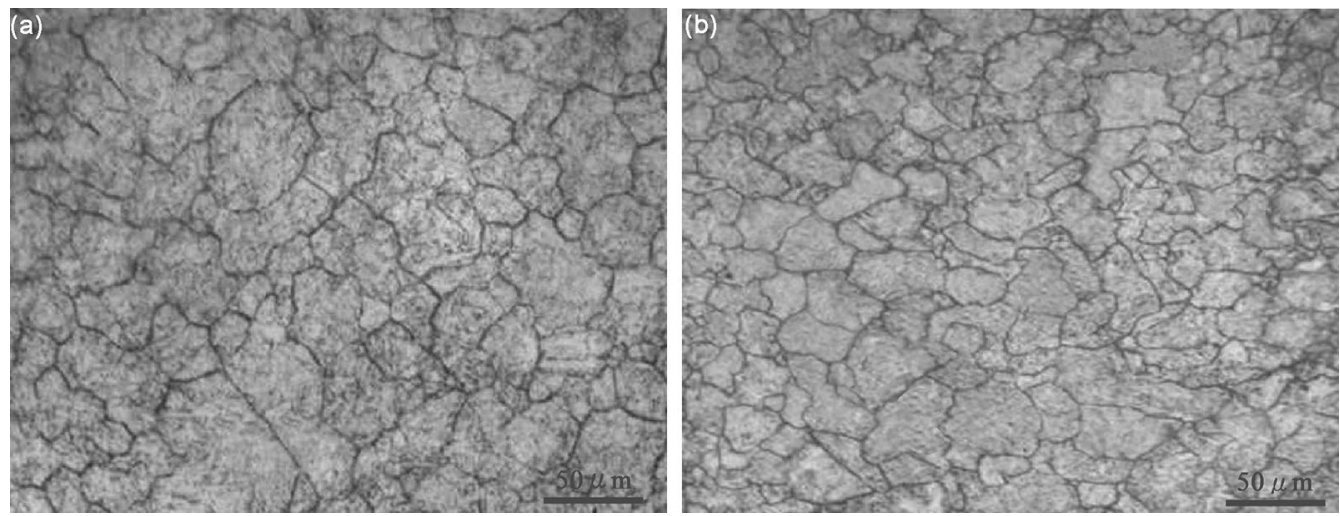

Fig. 8 Optical microstructures of V1 and V3 steels deformed at $950{ }^{\circ} \mathrm{C}, 0.01 \mathrm{~s}^{-1}$ : a V1 steel; $\mathbf{b} \mathrm{V} 3$ steel
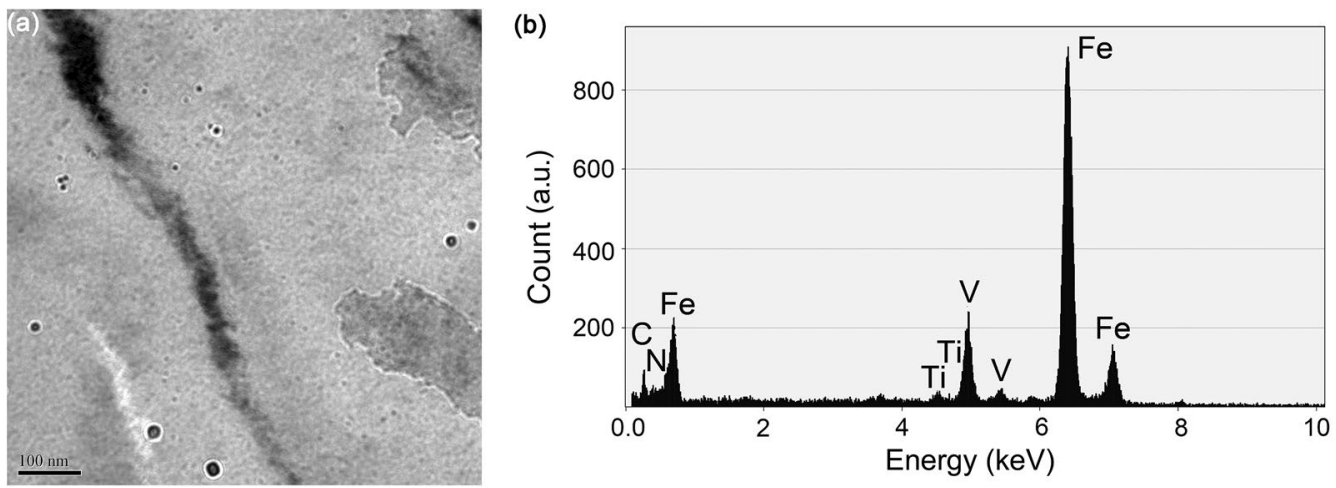

Fig. 9 TEM micrograph and EDX analysis of precipitates in V3 steel: a morphology of precipitates; $\mathbf{b}$ EDX analysis result of precipitate

precipitates may be formed in austenite depending on the austenitizing temperature and vanadium content, thus affecting on the hot deformation behavior of experimental steels.

The austenitizing temperature of experimental steels before hot deformation testing is $1200{ }^{\circ} \mathrm{C}$, and as a result, vanadium precipitates are fully solutionized into the austenite. When the deformation temperature is higher than the solution temperature of vanadium precipitates, there is no effect of precipitates on the DRX through the pinning effect of precipitates. However, vanadium atoms solutionized in austenite hinder the dislocation motion through the solute drag effect [33], thus increasing the flow stress of experimental steels. With increasing the deformation temperature and the vanadium content, the amount of solid solute vanadium is more, and thereby, the flow stress of V3 steel gets higher than those of other two steels as shown in Fig. 1. On the other hand, when the deformation temperature is $900{ }^{\circ} \mathrm{C}$ in V2 steel and is $900-950{ }^{\circ} \mathrm{C}$ in V3 steel, the vanadium precipitates can be formed during hot deformation and delay the occurrence of DRX. The formed vanadium precipitates hinder the dislocation motion through the pinning effect of precipitates, resulting in the increase in flow stress of experimental steels. The solute drag effect of solute vanadium on the increase in flow stress is less than the pinning effect of vanadium precipitates [33]. When the deformation temperature is low $\left(900-950^{\circ} \mathrm{C}\right), \mathrm{V} 3$ steel has more precipitates than V1 or V2 steel under the same deformation condition, and therefore, the flow stress of $\mathrm{V} 3$ steel at low deformation temperature is more increased than those of other two steels. Whereas, when the deformation tempertures are above $950^{\circ} \mathrm{C}$, the differences of flow stress among the experimental steels are decreased. This can be clearly seen from Fig. 1.

\subsection{Effect of Vanadium on DRX}

\subsubsection{Critical Stress and Strain}

To investigate the effect of vanadium content on DRX behavior, the peak stress (peak strain) and critical stress (critical strain) were analyzed. As shown in Fig. 4a, b, the peak stress of V3 steel is higher than that of V1 or V2 steel under the same deformation condition, indicating the increase in vanadium content in boron microalloyed steel leads to the increase in flow stress. The difference of the peak (critical) stress between V1 and V3 steels increases 
with decreasing deformation temperature. As mentioned above, this phenomenon demonstrates that the amount of vanadium precipitates in $\mathrm{V} 3$ steel is increased with decreasing the deformation temperature at low strain rate and pinning effects of precipitates are enhanced, making the DRX process delay. On the other hand, as shown in Fig. 4c, d, the peak and critical strain of V3 steel has higher tendency than V1 steel under the same deformation condition. (It should be noted that some curves show deviation from theoretical values due to the experimental error.) Hence, it is supposed that the vanadium content has little effect on these parameters.

Based on the characteristic points, the ratios of critical stress (strain) to peak stress (strain) are calculated and the results are shown in Fig. 10. As shown in Fig. 10, there is a linear relationship between $\sigma_{\mathrm{c}}\left(\varepsilon_{\mathrm{c}}\right)$ and $\sigma_{\mathrm{p}}\left(\varepsilon_{\mathrm{p}}\right)$, and those are calculated by linear regression as $\sigma_{\mathrm{c}}=0.915 \sigma_{\mathrm{p}}, \varepsilon_{\mathrm{c}}=0.471 \varepsilon_{\mathrm{p}}$ for V1 steel and $\sigma_{\mathrm{c}}=0.867 \sigma_{\mathrm{p}}, \varepsilon_{\mathrm{c}}=0.441 \varepsilon_{\mathrm{p}}$ for V3 steel, respectively. In this case, the ratio of $\varepsilon_{\mathrm{c}}$ to $\varepsilon_{\mathrm{p}}$ for $\mathrm{V} 3$ steel is less than V1 or V2 steel. This indicates that the increase in vanadium content decreases softening ability of DRX and increases strain strengthening ability. The ratio of $\varepsilon_{\mathrm{c}}$ to $\varepsilon_{\mathrm{p}}$ is reported differently in the studies. In the previous reports, the ratio of $\varepsilon_{\mathrm{c}}$ to $\varepsilon_{\mathrm{p}}$ often takes values between 0.6 and 0.8 [35-37] and for some microalloyed steels, the low values of $0.4-0.55$ have been also reported $[13,20]$. The parameters obtained in the experiment are in reasonable agreement with the previous researches $[16,20]$ on vanadium microalloyed steel.

\subsubsection{DRX Kinetics}

DRX is one of the important softening mechanisms of experimental steels. In general, it is difficult to determine the DRX volume fraction by the microstructure observation. DRX volume fraction $X$ can be derived from flow curves and described as following equation [38, 39].

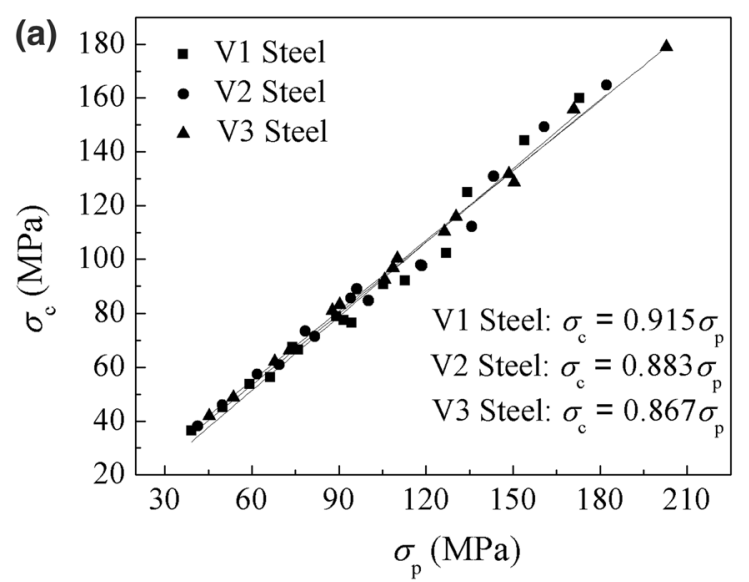

$X=\left(\sigma_{\mathrm{p}}-\sigma\right) /\left(\sigma_{\mathrm{p}}-\sigma_{s}\right)$,

where $\sigma_{\mathrm{p}}$ is the peak stress, $\sigma_{\mathrm{s}}$ is the steady-state stress, and $\sigma$ is the specific stress from flow curves.

As a kinetics model of DRX, the following Avrami equation is widely used [27, 31].

$X=1-\exp \left(-k\left(\left(\varepsilon-\varepsilon_{\mathrm{c}}\right) / \varepsilon_{\mathrm{p}}\right)^{n}\right)$,

where $k$ and $n$ are the material constants, $\varepsilon$ is the true strain, and $\varepsilon_{\mathrm{c}}$ and $\varepsilon_{\mathrm{p}}$ are the critical strain and peak strain, respectively.

To determine the values of $k$ and $n$, taking the twice natural logarithm of Eq. (16), following equation is obtained.

$\ln \ln (1 /(1-X))=\ln k+n \ln \left(\left(\varepsilon-\varepsilon_{\mathrm{c}}\right) / \varepsilon_{\mathrm{p}}\right)$.

The linear relationship between $\ln \ln (1 /(1-X))$ and $n \ln \left(\left(\varepsilon-\varepsilon_{\mathrm{c}}\right) / \varepsilon_{\mathrm{p}}\right)$ under different deformation conditions is observed as shown in Fig. 11. The average values of $k$ and $n$ are calculated by the linear regression analysis. The values of $k$ for V1, V2 and V3 steels are determined as $0.2012,0.1962$ and 0.1329 and the values of $n$ as 2.1638, 2.1976 and 2.1881, respectively. Thus, the kinetics model of DRX for these three experimental steels can be obtained as follows.

V1 steel $: X=1-\exp \left(-0.2012\left(\left(\varepsilon-\varepsilon_{\mathrm{c}}\right) / \varepsilon_{\mathrm{p}}\right)^{2.1638}\right)$,

V2 steel $: X=1-\exp \left(-0.1962\left(\left(\varepsilon-\varepsilon_{\mathrm{c}}\right) / \varepsilon_{\mathrm{p}}\right)^{2.1976}\right)$,

V3 steel $: X=1-\exp \left(-0.1329\left(\left(\varepsilon-\varepsilon_{\mathrm{c}}\right) / \varepsilon_{\mathrm{p}}\right)^{2.1881}\right)$.

Based on the above model, the effects of deformation temperature, strain and vanadium content on the DRX volume fraction are shown in Fig. 12. It can be seen that all

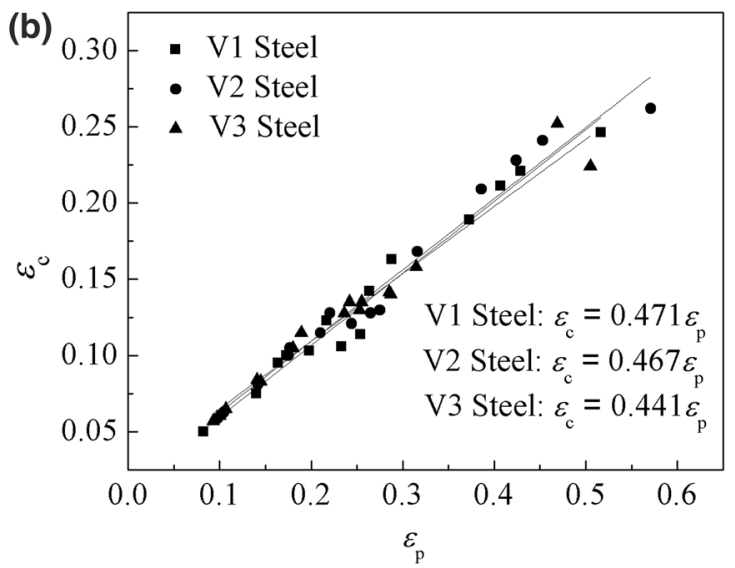

Fig. 10 Relationship between characteristic points: $\mathbf{a} \sigma_{\mathrm{p}}$ and $\sigma_{\mathrm{c}} ; \mathbf{b} \varepsilon_{\mathrm{p}}$ and $\varepsilon_{\mathrm{c}}$ 

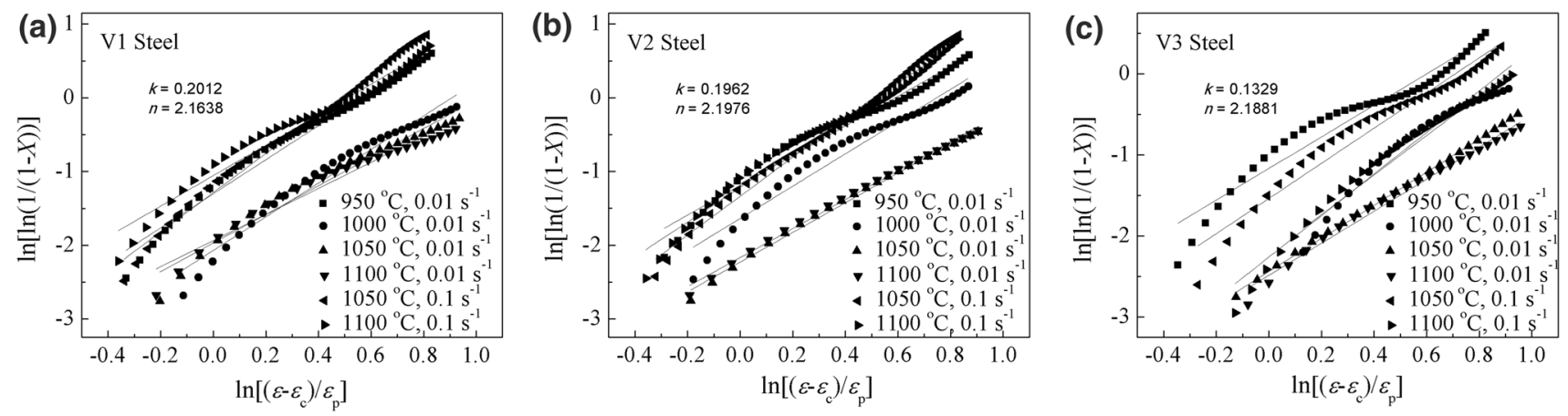

Fig. 11 Relationship between $\ln [\ln (1 /(1-X))]$ and $\left.\ln \left[\left(\varepsilon-\varepsilon_{\mathrm{c}}\right) / \varepsilon_{\mathrm{p}}\right)\right]$ under different deformation conditions: a V1 steel; b V2 steel; c V3 steel
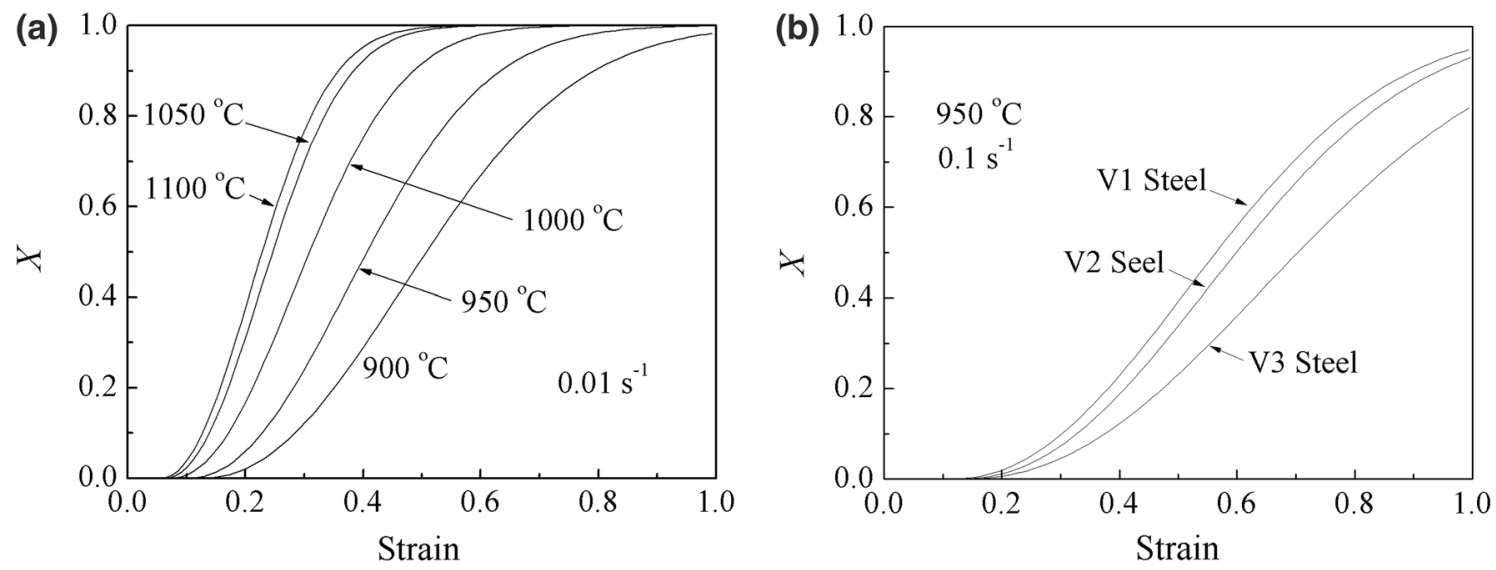

Fig. 12 DRX volume fraction at strain rate of $0.01 \mathrm{~s}^{-1}$ and different deformation temperatures for V1 steel a; kinetics of DRX for three experiment steels under the same deformation condition $\left(950{ }^{\circ} \mathrm{C}, 0.1 \mathrm{~s}^{-1}\right) \mathbf{b}$

the curves exhibit ' $S$ ' shapes and the DRX volume fraction increases with increasing the deformation temperature and the strain. And the DRX kinetics is faster at the lower strain rate and the higher deformation temperature. Figure 13 shows the optical microstructures of the three experimental steels deformed at temperature of $950{ }^{\circ} \mathrm{C}$ and the strain rate of $0.1 \mathrm{~s}^{-1}$. In $\mathrm{V} 3$ steel, many new fine DRX grains were formed, but there still existed some original grains elongated along the deformation direction. As compared V1 or V2 steel with V3 steel, the original grains were mainly replaced by new DRX grains. From Figs. 12 and 13, it can be clearly seen that the DRX volume fraction for V1 or V2 steel is higher than that for V3 steel at the same strain. This indicates that the addition of vanadium in the boron microalloyed steel caused a delay of DRX kinetics during hot deformation. This is in good agreement with the result that the
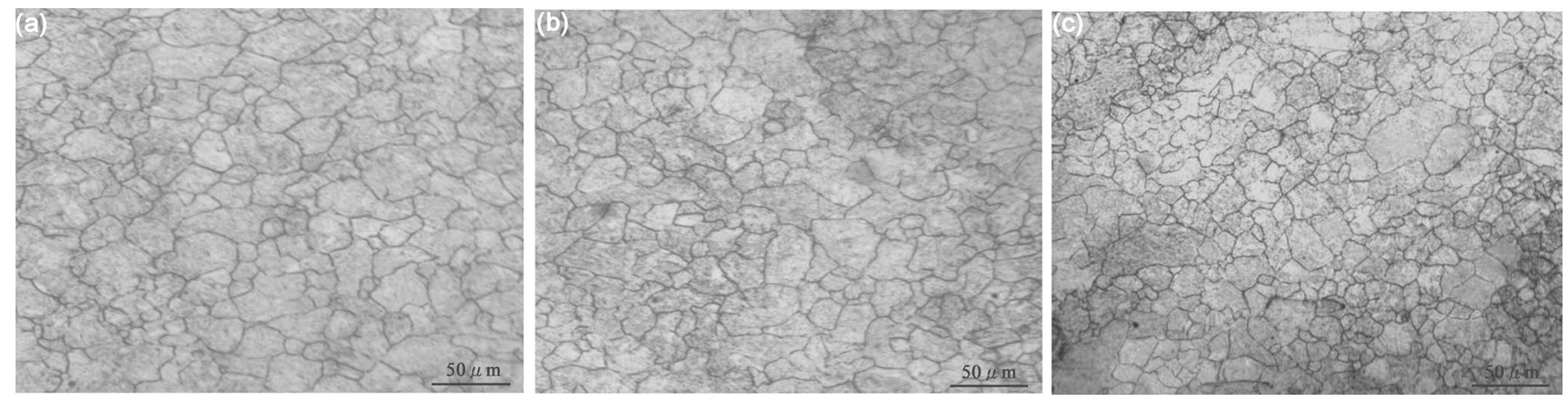

Fig. 13 Optical microstructures of three experimental steels deformed at $950{ }^{\circ} \mathrm{C}, 0.1 \mathrm{~s}^{-1}$ : a V1 steel; b V2 steel; c V3 steel 
activation energy for hot deformation of $\mathrm{V} 3$ steel is higher than both V1 and V2 steels.

\section{Conclusions}

The influence of vanadium content $(0.042,0.086$ and $1.8 \mathrm{wt} \%)$ on the hot deformation behavior in low-carbon boron microalloyed steel was studied at the deformation temperature of $900-1100{ }^{\circ} \mathrm{C}$ and at the strain rate of $0.01-10 \mathrm{~s}^{-1}$. The research results are as follows.

(1) The flow curves of experimental steels exhibit typical DRX behavior at the low strain rate of $0.01-0.1 \mathrm{~s}^{-1}$ and typical DRV behavior at the high strain rate of $10 \mathrm{~s}^{-1}$.

(2) The flow stress constitutive equations of experimental steels were developed with the activation energy. The activation energy for hot deformation increases with increasing vanadium content. The activation energy of the steel containing $0.18 \mathrm{wt} \% \mathrm{~V}\left(316.5 \mathrm{~kJ} \mathrm{~mol}^{-1}\right)$ is significantly higher than both 0.42 and $0.086 \mathrm{wt} \% \mathrm{~V}$ steels (282.7 and $284.6 \mathrm{~kJ} \mathrm{~mol}^{-1}$, respectively).

(3) The hot deformation flow stress of experimental steels increases with the increase in vanadium content. When the vanadium content is less than $0.086 \mathrm{wt} \%$, there is no significant difference between them; when the vanadium content is increased to $0.18 \mathrm{wt} \%$, the flow stress remarkably increases due to the increase in the solute drag and/or pinning effect of vanadium.

(4) The peak stress (peak strain) and critical stress (critical strain) increase with increasing the vanadium content, indicating the addition of vanadium in the boron microalloyed steel can delay the initiation of DRX. The relation between peak stress (strain) and critical stress (strain) was obtained as $\sigma_{\mathrm{c}}=(0.867-0.915) \sigma_{\mathrm{p}}$, $\varepsilon_{\mathrm{c}}=(0.441-0.471) \varepsilon_{\mathrm{p}}$ in experimental steels.

(5) The DRX kinetics of the steel containing $0.18 \mathrm{wt} \% \mathrm{~V}$ is lower than both 0.42 and $0.086 \mathrm{wt} \% \mathrm{~V}$ steels in the same deformation condition, which shows that addition of vanadium can delay the DRX process.

Acknowledgements This work was supported by the Kim Chaek University of Technology of DPR of Korea and the State Key Laboratory of Rolling and Automation of Northeastern University of China.

\section{References}

[1] S.M. Hong, J.H. Lee, K.S. Park, S.H. Lee, Mater. Sci. Eng. A 589, $165(2014)$
[2] A. Terzic, M. Calcagnotto, S. Guk, T. Schulz, R. Kawalla, Mater. Sci. Eng. A 584, 32 (2013)

[3] Y.L. Gao, X.X. Xue, H. Yang, ISIJ Int. 56, 619 (2016)

[4] Y.J. Li, D. Ponge, P. Choi, D. Raabe, Scr. Mater. 96, 13 (2015)

[5] A. Terzic, M. Calcagnotto, S. Guk, T. Schulz, R. Kawalla, Sci. Eng. A 584, 32 (2013)

[6] S. Yoshida, K. Ushioda, J. Ågren, ISIJ Int. 54, 685 (2014)

[7] H. Yang, X.X. Wang, J.B. Qu, J. Iron Steel Res. Int. 21, 787 (2014)

[8] L.Y. Lan, C.L. Qiu, P. Zhou, D.W. Zhao, C.M. Li, X.H. Gao, L.X. Du, Acta Metall. Sin. (Engl. Lett.) 24, 486 (2011)

[9] H.F. Lan, L.X. Du, R.D.K. Misra, Mater. Sci. Eng. A 611, 194 (2014)

[10] T.N. Baker, Mater. Sci. Technol. 25, 1083 (2009)

[11] K.S. Kim, L.X. Du, C.R. Gao, Acta Metall. Sin. (Engl. Lett.) 28, 692 (2015)

[12] I. Mejía, A. Bedolla-Jacuinde, C. Maldonado, J.M. Cabrera, Mater. Sci. Eng. A 528, 4468 (2011)

[13] H.L. Wei, G.Q. Liu, H.T. Zhao, M.H. Zhang, Mater. Sci. Eng. A 596, $112(2014)$

[14] J.J. Jonas, Mater. Sci. Eng. A 184, 155 (1994)

[15] H.L. Wei, G.Q. Liu, X. Xiao, M.H. Zhang, Mater. Sci. Eng. A 573, 215 (2013)

[16] S.K. Badjena, ISIJ Int. 54, 650 (2014)

[17] A.M. Elwazri, P. Wanjara, S. Yue, Mater. Sci. Eng. A 339, 209 (2003)

[18] M. Meysami, S.A.A.A. Mousavi, Mater. Sci. Eng. A 528, 3049 (2011)

[19] S.F. Medina, C.A. Hernandez, Acta Mater. 44, 137 (1996)

[20] B.C. Zhao, T. Zhao, G.Y. Li, Q. Lu, Mater. Sci. Eng. A 604, 117 (2014)

[21] G.Z. Quan, A. Mao, G.C. Luo, J.T. Liang, D.S. Wu, J. Zhou, Mater. Des. 52, 98 (2013)

[22] Y.C. Lin, M.S. Chen, J. Zhong, Mater. Process. Technol. 205, 308 (2008)

[23] E.I. Poliak, J.J. Jonas, ISIJ Int. 43, 692 (2003)

[24] E.I. Poliak, J.J. Jonas, ISIJ Int. 43, 684 (2003)

[25] J.J. Jonas, X. Quelennec, L. Jiang, E. Martin, Acta Mater. 57, 2748 (2009)

[26] C. Zener, J.H. Hollomon, J. Appl. Phys. 15, 22 (1944)

[27] P. Zhou, Q.X. Ma, Acta Metall. Sin. (Engl. Lett.) 30, 907 (2017)

[28] N.P. Jin, H. Zhang, Y. Han, W.X. Wu, J.H. Chen, Mater. Charact. 60, 530 (2009)

[29] X.F. Zhou, J. Plast. Eng. 14, 20 (2007)

[30] C.M. Sellars, W.J. Mc, G. Tegart, Mem. Sci. Rev. Metall. 63, 731 (1966)

[31] Y.L. Gao, X.X. Xue, H. Yang, Acta Metall. Sin. (Engl. Lett.) 28, 931 (2015)

[32] T. Siwecki, J. Eliasson, R. Lagneborg, ISIJ Int. 50, 760 (2010)

[33] M.G. Akben, I. Weiss, J.J. Jonas, Acta Metall. 29, 114 (1981)

[34] K. Narita, ISIJ Int. 15, 145 (1975)

[35] C. Devadas, I.V. Samarasekera, E.B. Hawbolt, Metall. Trans. A 22, 335 (1991)

[36] H. Mirzadeh, J.M. Cabrera, J.M. Prado, A. Najafizadeh, Mater. Sci. Eng. A 528, 3876 (2011)

[37] G.R. Ebrahimi, H. Keshmiri, A.R. Maldar, A. Momeni, J. Mater. Sci. Technol. 28, 467 (2012)

[38] M.H. Wang, Y.F. Li, W.H. Wang, J. Zhou, A. Chiba, Mater. Des. 45, 384 (2013)

[39] A. Momeni, H. Arabi, A. Rezaei, H. Badri, S.M. Abbasi, Mater. Sci. Eng. A 528, 2158 (2011) 